\title{
Análisis y proyección de los contenidos audiovisuales sobre jóvenes y drogas en YouTube
}

\author{
Nereida LÓPEZ VIDALES \\ Universidad de Valladolid \\ nereida.lopez@hmca.uva.es \\ Leire GómEz RuBio \\ Universidad de Valladolid \\ leire.gomez@hmca.uva.es
}

Recibido: 9 de mayo de 2014

Aceptado: 18 de noviembre de 2014

\begin{abstract}
Resumen
Internet se ha convertido en un escaparate más a través del que los diferentes organismos e instituciones, tanto públicas como privadas, así como ciudadanos en general, difunden sus mensajes. Entre ellos se encuentran las campañas contra la drogadicción que, a pesar de continuar apostando de forma mayoritaria por su divulgación a través de los medios convencionales, han encontrado en la Red un nuevo canal de transmisión, especialmente de las producciones amateur. En este trabajo ${ }^{1}$ se ofrece un análisis de los vídeos relacionados con las drogas más vistos a través del canal-web de vídeos con mayor número de visitas en España, YouTube.
\end{abstract}

Palabras clave: jóvenes, drogas, youtube, prevención, educación.

\section{Analysis and projection of audiovisual contents about youth and drugs in YouTube}

\begin{abstract}
The Internet has become the showroom for different agencies and institutions, both public and private, as well as for citizens in general, where to spread their message. Among them we can find campaigns against drug addiction and despite their largely betting through conventional mainstream media, have recently found in the net a new transmission channel, especially for amateur productions. In this paper it is offered an analysis of those videos related to drugs most viewed in the most visited video site in Internet, YouTube.
\end{abstract}

Keywords: Young, drugs, youtube, prevention, education.

\section{Referencia normalizada}

LÓPEZ VIDALES, Nereida y GÓMEZ RUBIO, Leire (2015): “Análisis y proyección de los contenidos audiovisuales sobre jóvenes y drogas en YouTube". Estudios sobre el Mensaje Periodístico. Vol. 21, Núm. 2 (julio-diciembre), págs.: 863-881. Madrid, Servicio de Publicaciones de la Universidad Complutense.

Sumario: 1.Introducción; 1.1. Panorama actual y estrategias de intervención; 1.2. Campañas de prevención y medios de comunicación. 2. El estudio: las campañas de prevención de consumo de drogas para jóvenes en YouTube; 2.1. Objetivos y planteamiento del análisis; 2.2. Metodología cualitativa. 3. La proyección de las campañas contra las drogas en YouTube. Análisis e interpretación; 3.1. Aproximación a los resultados: ideas generales; 3.2. El mensaje: elementos, percepción e interpretación; 3.3. El formato y la duración no lo son todo; 3.4. Los destinatarios de las campañas: jóvenes y de ambos sexos; 3.5. Drogas y redes sociales: participación ciudadana en la difusión del mensaje. 4. Conclusiones. 5. Referencias bibliográficas.

1 Este artículo de investigación forma parte del estudio "Jóvenes y drogas: percepción de las campañas de prevención del consumo juvenil de drogas (2013-2016)"; CÓDIGO: OCENDIO61316. 


\section{Introducción}

El consumo de drogas es un problema social de primer orden que tiene graves consecuencias no sólo a nivel individual sino también colectivo.

En décadas pasadas, años 80 y 90 del siglo XX, el consumo de drogas se asociaba principalmente a la heroína y a un tipo de consumidor compulsivo, marginal, conflictivo y relacionado, casi siempre, con la delincuencia (EDE, 2010:1). En los primeros años de 2000, sin embargo, esta sustancia pasó a ser algo residual, frente a otras drogas como el alcohol, el cannabis, la cocaína y las drogas de síntesis, que alcanzaron una enorme popularidad -no sólo entre los más jóvenes-, y se acompañan de un menor deterioro físico. Sin embargo, en la actualidad, la heroína parece volver a presentar un cierto repunte en su consumo, en especial como sustitutivo de los analgésicos, a la par que se observa un aumento en el consumo de alcohol entre los menores y de medicamentos sin receta como consecuencia de la crisis económica (PNSD, 2013-2016: 46).

La edad a la que se inicia el consumo de drogas suele ser la adolescencia o la primera juventud, de ahí que suponga una enorme preocupación para familias e instituciones, que vuelcan sus esfuerzos principalmente en la prevención de la drogadicción. Son muchas las campañas institucionales, públicas y privadas, que se han lanzado desde los 90 en España con el objetivo de contribuir a la prevención del consumo de drogas entre los sectores más jóvenes de la sociedad. La mayoría de ellas han hecho hincapié en la extensión de la información sobre sus efectos y consecuencias entre la población considerada más vulnerable, participando en la educación temprana desde colegios e institutos de secundaria, de modo que se contribuyera a retrasar la edad de inicio en el consumo.

El éxito potencial de estas campañas y la asunción del problema como una responsabilidad social que excede del entorno próximo del drogadicto, unido a la disminución del consumo general con respecto a décadas pasadas, ha conducido a la situación actual en la que el consumo de drogas se percibe como un peligro social de "bajo riesgo". Según el último estudio del Centro de Investigaciones Sociológicas, la sociedad española considera que las drogas no representan un problema de primer orden, situando su importancia al mismo nivel que, por ejemplo, las infraestructuras, la Ley del aborto o las hipotecas, muy por debajo de otros temas como el paro, la política/los políticos o la corrupción (CIS, 2014: 8).

La realidad apunta a que han cambiado los patrones de consumo de drogas, al tiempo que en la percepción de los riesgos que entraña, especialmente entre el público juvenil, "se ha producido un proceso de normalización e integración. En las calles no se ve a las personas adictas a sustancias, mientras que hace algunos años tenían un fuerte impacto visual, con ejemplos de gran deterioro físico y marginación social. Muchos consumidores se han hecho invisibles a la sociedad" (Robles, 2009: 125). También la tipología de los consumidores se ha visto ampliada hacia individuos de clases más elevadas y con mayores niveles culturales, fundamentalmente, en torno a las llamadas drogas legales tales como el alcohol.

A esta realidad hay que añadirle la constatación de un cambio cultural generalizado en el que la creciente presencia de los medios de comunicación y las nuevas tecnolo- 
gías ocupan un papel de primer orden en la transformación de las relaciones interpersonales y la comunicación, en general, de las nuevas generaciones: "Los ordenadores, los videojuegos, Internet, las cámaras digitales o los teléfonos móviles son básicos en sus vidas, en tanto que herramientas esenciales para comunicarse, compartir, consumir, participar o crear." (Tabernero et al., 2010: 77). La cantidad de adolescentes, por ejemplo, que crea y mantiene activamente espacios de comunicación, auto-presentación y contribución en la Red crece de manera constante (Tubella et al., 2008: 121).

Este tipo de actividades repercute de manera significativa en su dinámica de obtención y desarrollo de competencias a nivel social, cultural y educativo, es decir, en la manera que tienen de comunicarse, consumir, trabajar, estudiar, colaborar y resolver problemas. Internet es para ellos más un espacio de ocio que de información al estilo tradicional de la adquisición del conocimiento. Sobre este conocimiento, además, hay que recordar que, ya sea a nivel social, cultural, profesional o técnico, se comparte de manera informal -los que más experiencia tienen comparten con los recién iniciados-, y este proceso merece el reconocimiento de todos los implicados (Jenkins et al., 2008), así como el de toda la comunidad que se construye al tiempo en las redes sociales.

En consecuencia, los jóvenes de hoy adquieren y comparten conocimiento y experiencias a través de Internet, especialmente mediante las redes sociales -Facebook y Twitter-, la aplicación para móviles Whatsapp y el canal de vídeos YouTube. Los medios de comunicación convencionales son los menos elegidos por las nuevas generaciones para informarse por lo que podríamos intuir que para medir el éxito de una campaña de prevención de la drogadicción, resultaría útil observar también qué contenidos relacionados comparten mediante estos nuevos canales y cómo participan en su difusión y distribución.

\subsection{Panorama actual y estrategias de intervención}

España se sitúa a la cabeza de la Unión Europea en consumo de cocaína y cannabis, especialmente entre los jóvenes, aunque el uso de esas sustancias tiende a bajar en los últimos años después de haber tocado techo en el año 2008, según indica el Informe Anual del Observatorio Europeo de las Drogas de 2013.

Para abordar el problema del consumo de drogas se utilizan diversas estrategias de prevención: la prevención ambiental y universal, que se dirige a poblaciones completas; la prevención selectiva, que atiende a grupos vulnerables; y la prevención específica, que se centra en personas de riesgo.

En España, la edad de inicio de los jóvenes en el consumo de drogas se sitúa en torno a los 14 años. En el caso del alcohol esto significa un ligero descenso con respecto a años anteriores donde hay una diferencia de 0,8 entre los adolescentes de 15 a 18 años desde 1996 hasta 2008, por ejemplo (EDE, 2010: 135). De hecho, la proporción de jóvenes y adolescentes bebedores excesivos y de riesgo en los fines de semana se ha incrementado desde 2008 hasta alcanzar la cifra de un $25 \%$.

La edad media de inicio al cannabis, la droga ilegal por excelencia en el consumo juvenil, se mantiene estable en torno a los 17 años, y en el caso de la cocaína es a los 19 años. El consumo más temprano está relacionado, además de con el alcohol, con las anfetaminas, a partir de los 16 años. 
Las campañas de prevención en drogadicción tienden a establecer como público objetivo a los jóvenes de 18 a 25 años. Ahora, además, deben centrar su mirada no sólo en el joven, sino en su familia y su entorno, dentro del cual es relevante el centro escolar o ámbito educativo y la nueva forma de relacionarse con los demás, especialmente mediante las nuevas herramientas 2.0. La idea contenida es superar la fase de información para promover una fase más profunda de concienciación.

\subsection{Campañas de prevención y medios de comunicación}

Los programas preventivos buscan, por lo general, ir más allá de la entrega de información para profundizar en la sensibilización del público con respecto al tema drogas. En su clasificación se tienen en cuenta cinco criterios: estrategia de intervención, contexto de aplicación, población a la que se dirigen, riesgo de la población objetivo y calidad del programa (EDE, 2010: 7). ${ }^{2}$

Los medios de comunicación que tradicionalmente han servido a los distintos organismo e instituciones, públicas y privadas, para realizar estas campañas han sido la prensa escrita, la radio, la televisión y la publicidad exterior. Sólo en el periodo comprendido entre 1988 y 2008 se llevaron a cabo un total de 47 campañas de carácter preventivo en materia de drogas, la mayoría de ellas realizadas por la Fundación de Ayuda contra la Drogadicción (FAD), seguidas de las impulsadas por el Plan Nacional sobre Drogas. De todas ellas, si atendemos al soporte en el que se transmitieron, la gran mayoría -43- lo hicieron a través de los medios tradicionales, prensa, radio y televisión, mientras que una de ellas estuvo presente exclusivamente en carteles y otra sólo se difundió por televisión. Las otras tres campañas restantes lo hicieron tanto en radio como en televisión. Sin embargo, ninguna de estas iniciativas incluyó como soporte Internet (Pereira y Espada, 2009: 281-286).

En todo caso, que las campañas de diferentes organismos nacionales e internacionales no hayan sido diseñadas para ser difundidas a través de Internet no quiere decir que sus contenidos no hayan encontrado en la Red un nuevo canal de difusión de sus mensajes, especialmente entre el público juvenil. Además, Internet ha abierto la puerta a la transmisión de creaciones audiovisuales individuales y/o amateur, entre las que destacan aquellas realizadas por los centros educativos dentro de sus programas curriculares de prevención en materia de drogodependencias. Si efectuamos un somero rastreo por la Red, resulta evidente cómo en los últimos años han ido proliferando los vídeos realizados por escolares, especialmente de Enseñanza Secundaria y Bachillerato, creaciones que se publican y conviven en Internet junto a las realizadas por organismos de mayor envergadura.

En este punto, conviene resaltar que mientras los medios de comunicación tradicionales (prensa, radio y televisión) continúan siendo las "principales vías" a través de las que la ciudadanía dice obtener información sobre drogas, los recursos ofreci-

2 Las campañas publicitarias están en relación directa con las estrategias de influencia en segmentos diversos de población: niños y adolescentes y padres o educadores, son los más habituales. Sobre su valoración final o eficacia hay, sin embargo, muy pocos estudios publicados. 
dos a través de Internet van consolidándose. Concretamente, el Observatorio Español de la Droga y las Toxicomanías (OEDT) señala que mientras un 30\% de la población española recibió en 2011 información sobre nuevas drogas a través de los medios de comunicación -frente al 39,4\% al que le gustaría que así fuera-, el 9,8\% dijo haberse informado a través de Internet (páginas web, foros y redes sociales), frente al 28,4\% al que le gustaría que fuera de este modo (Informe Nacional de España, 2012:80).

El canal-web más importante en la actualidad a través del que los jóvenes visualizan y comparten este tipo de productos audiovisuales es YouTube. A finales de 2013, YouTube era el sitio web de vídeos con más visitas, con un total de 19.032 de octubre a noviembre, frente a las 4.767 registradas por el Diario Marca, segundo sitio más visitado por los internautas. Esta cifra representa un aumento de más de 2.000 visitas con respecto al mismo periodo del año anterior, donde se registraron 16.956 entradas (AIMC, 2013), pero sobre todo indica el alto potencial de este canal para la difusión de las campañas de prevención en drogadicción.

\section{El estudio: las campañas de prevención de consumo de drogas para jóvenes en YouTube}

\subsection{Objetivos y planteamiento del análisis}

Nuestro objetivo se centra en profundizar en el conocimiento de cómo percibe el público joven la información presente en estas campañas a través de los nuevos canales de comunicación, en este caso de YouTube, mediante el análisis de la naturaleza y características de las creaciones audiovisuales más visionadas en la Red. Esta información sería de un notable interés de cara a conocer mejor cuál es el éxito que tienen este tipo de acciones entre el segmento poblacional más expuesto al consumo de drogas.

Para ello, procederemos al análisis de los elementos que componen los vídeos más vistos recientemente en el canal YouTube, presentes en la segunda semana del mes de febrero de 2014 (del 10 al 16) y localizados bajo la etiqueta de investigación "jóvenes y drogas", que presenta el mejor funcionamiento para la búsqueda de contenidos relacionados con el tema planteado. La elección de la "etiqueta" se produce una vez descartadas otras próximas que eran menos dinámicas para los navegadores sociales y que terminaban por conducirnos a los mismos o similares contenidos audiovisuales. La selección del periodo responde a la necesidad de que la información recogida para esta aportación sea de actualidad para lo que se han tratado de localizar los últimos vídeos compartidos a través de YouTube; los años seleccionados han sido de 2008 a 2014. El ámbito determinado fue desde un principio nacional, España, aunque las listas de YouTube no establecen este criterio como diferenciador o clasificador de los contenidos publicados en relación al tema de la drogadicción y las campañas de prevención hacia los jóvenes. Al contrario, como veremos más adelante, los vídeos más visitados en Internet tienen procedencias nacionales muy dispares y, entre los 20 primeros por ejemplo, aparecen recogidos cuatro vídeos del Gobierno Chileno, uno de Argentina, dos de ONG latinoamericanas, tres de instituciones mejicanas y cuatro españolas, entre otras, a pesar de buscar insistentemente con la etiqueta "España".

La cantidad de vídeos publicados que se establecieron para el estudio fue inicialmente de 20, número de contenidos a mostrar por página de forma general, si no se 
utiliza otro criterio personalizado. Sin embargo, la cantidad hubo de reducirse a 10 finalmente al comprobar durante varias semanas que el orden de los vídeos no se alteraba con el paso del tiempo y porque además el número de visitas recibidas era poco significativo para añadirlos al estudio.

Para la selección de nuestra muestra hemos tenido en cuenta:

- Que los vídeos fueran institucionales o particulares, estuvieran destinados a los jóvenes dentro de campañas de prevención de la drogadicción

- Que su publicación fuese reciente, en todo caso posterior a 2008

- Que el número de visitas fuera elevado, por encima de 80.000 visitas

- Que el contenido fuese audiovisual, con audio e imagen

Las hipótesis de partida son, por un lado, que la recepción de estos vídeos a través de YouTube entre los jóvenes no es tan importante en número como cabría intuir por la actual "vida/cultura digital" de este sector poblacional; y por otro, que, sin embargo, son los vídeos creados por jóvenes y adolescentes los que llegan antes a Internet y se comparten más dentro de su comunidad de relaciones. Este tipo de contenidos se basan preferentemente en un código visual, son más breves y más fáciles de compartir que aquellos otros realizados por las instituciones en sus campañas de prevención.

En consecuencia, en las siguientes páginas se expone cuál es el papel que YouTube juega como escaparate y canal para el visionado de este tipo de vídeos, a los que hemos clasificado en dos categorías: aquellos realizados por particulares y videoaficionados y los creados por organismos institucionales, asociaciones y/o medios de comunicación.

\subsection{Metodología cualitativa}

Para el análisis de los vídeos seleccionados utilizamos una estrategia común de análisis cualitativo en el que combinamos varias técnicas complementarias: búsqueda documental para establecer un marco de referencia para el estudio e identificar los contenidos audiovisuales más visitados en YouTube, consulta de fuentes secundarias para elaborar una breve descripción del consumo actual de drogas por parte de los jóvenes, y un análisis de contenido de los vídeos seleccionados como muestra del estudio como herramienta fundamental para la recogida de información.

Para abordar el análisis de contenido de los 10 vídeos seleccionados se ha procedido a la elaboración de una ficha que recoge las variables que hemos considerado relevantes en la codificación de la información, distribuidas por bloques, tomando como referencia algunos estudios recientes sobre las campañas contra la drogadicción en España ${ }^{3}$. Las dimensiones que se han tenido en cuenta, a partir de estos estudios, son: el código audiovisual (la forma del mensaje), el código audio (significado de voz, música, silencio y efectos), el código visual (significado de las imágenes), los persona-

3 Los estudios tenidos en cuenta han sido: UNIVERSITAT JAUME I (2006): Análisis de campañas de comunicación social. Castellón: Universitat Jaume I. Informe; EDE (2010): Análisis de los anuncios televisivos de las campañas de prevención de drogodependencias y su incidencia en la población adolescente y juvenil. Bilbao: EDE y Gobierno Vasco. 
jes (protagonistas e interacción) y el mensaje (aspectos del discurso o mensaje de la campaña). Finalmente, recogemos el tráfico de estos vídeos a través de las redes sociales para observar su proyección entre la comunidad.

\section{La proyección de las campañas contra las drogas en YouTube. Análisis e inter- pretación}

Bajo la etiqueta de búsqueda en Internet elegida para la investigación, “jóvenes y drogas", YouTube albergaba durante la segunda semana de febrero más de 66.000 resultados. De ellos, entre los diez primeros que registraron el mayor número de reproducciones o visitas por parte de los internautas -seleccionados como muestra definitiva- se encontraban:

Tabla 1. Los diez vídeos más vistos en YouTube bajo la etiqueta de "jóvenes y drogas". Fuente: elaboración propia

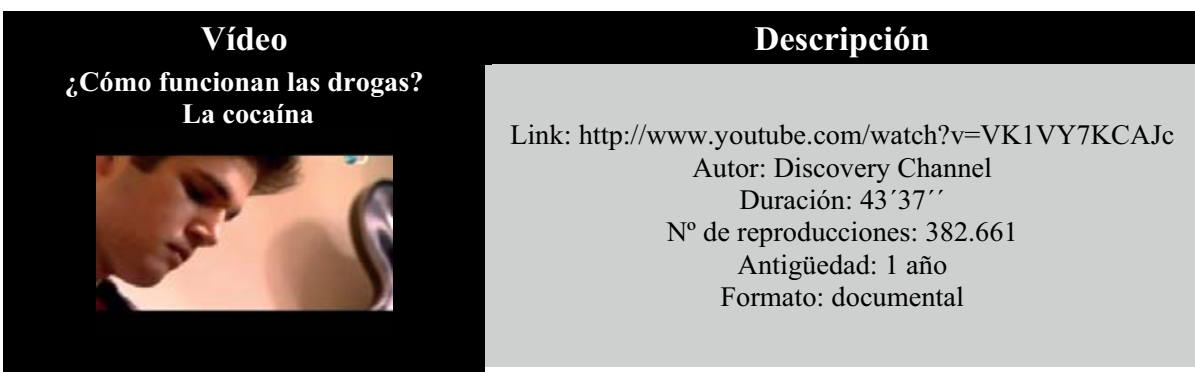

La droga y el sida obra de teatro El evangelio cambia

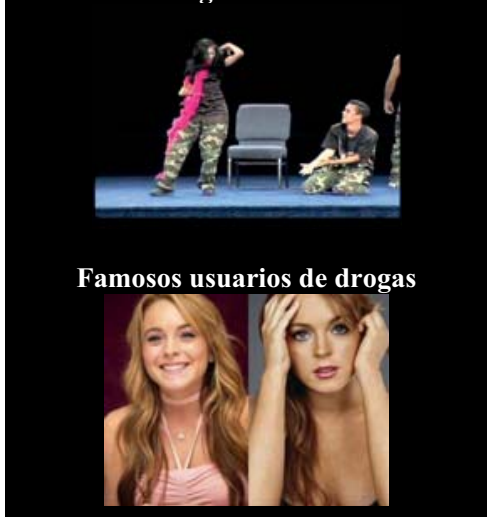

La verdad sobre las drogas

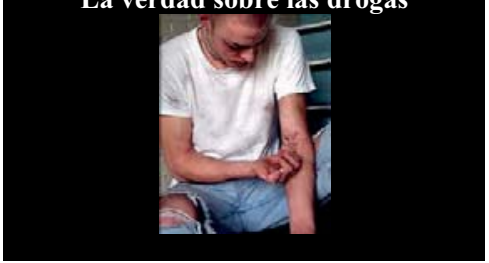

Link: http://www.youtube.com/watch?v=gaibwEIPYNk Autor: Somos Imperio Joven Duración: 4'09'

$\mathrm{N}^{\circ}$ de reproducciones: 322.663 Antigüedad: 1 año Formato: teatro

Link: http://www.youtube.com/watch?v=zNOLG4MSGGQ Autor: Itanália Fernanda Duración: 5'01'

$\mathrm{N}^{\circ}$ de reproducciones: 273.170 Antigüedad: 4 años Formato: vídeoaficionado

Link: http://www.youtube.com/watch?v=0KL0py7i0nA Autor: Fundación por un mundo libre de drogas Duración: 7'54'"

$\mathrm{N}^{\circ}$ de reproducciones: 158.814

Antigüedad: 3 años

Formato: documental 


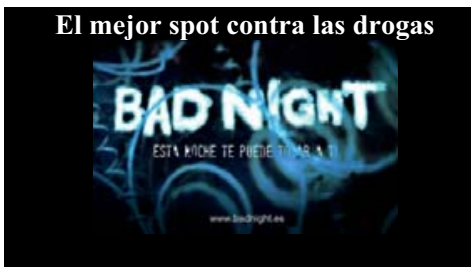

\section{Campaña mundial contra la droga}

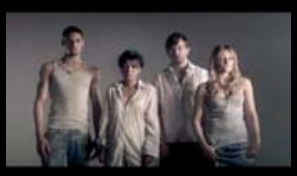

Malditas drogas

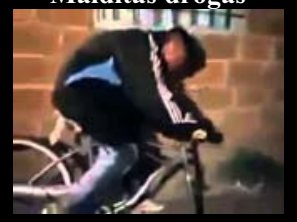

Una vida libre de drogas y alcohol

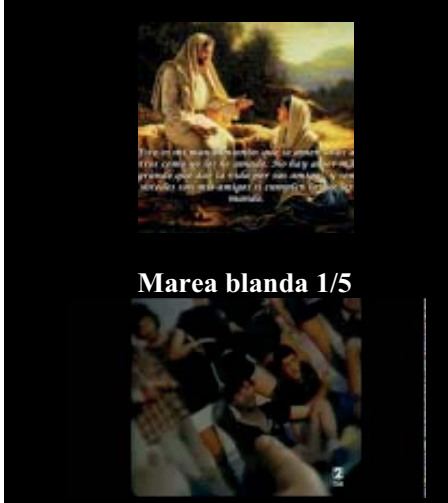

Consecuencias de las drogas

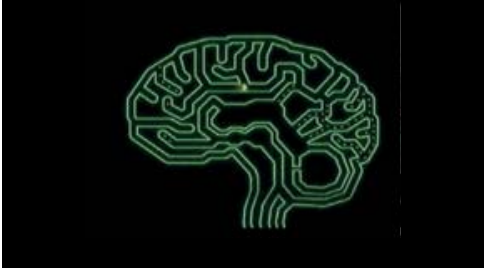

Link: http://www.youtube.com/watch?v=BDxQUR6s6oo Autor: FAD

Duración: 32"

$\mathrm{N}^{\mathrm{o}}$ de reproducciones: 109.338

Antigüedad: 4 años

Formato: spot

Link: http://www.youtube.com/watch?v=ioiiiemPK7A

Autor: United Nations Office on Drugs and Crime

Duración: 1'11'

$\mathrm{N}^{\circ}$ de reproducciones: 103.539

Antigüedad: 3 años

Formato: campaña mundial

Link: http://www.youtube.com/watch? $\mathrm{v}=$ UirhsdCG6xQ

Autor: particular

Duración: '46"

$\mathrm{N}^{\circ}$ de reproducciones: 98.201

Antigüedad: 5 años

Formato: vídeoaficionado

Link: http://www.youtube.com/watch?v=eiPx7qlMwk0

Autor: particular

Duración: 7'56"

$\mathrm{N}^{\circ}$ de reproducciones: 95.716

Antigüedad: 5 años

Formato: vídeoaficionado

Link: http://www.youtube.com/watch?v=U3JOwJKCBUk Autor: Documentos TV

Duración: 9'43"'

$\mathrm{N}^{\circ}$ de reproducciones: 84.131

Antigüedad: 4 años

Formato: documental

Link: http://www.youtube.com/watch?v=mxqH819uDj8

Autor: particular

Duración: 6'54'

$\mathrm{N}^{\circ}$ de reproducciones: 69.269

Antigüedad: 5 años

Formato: conjunto de comerciales 
La primera diferencia en estas obras audiovisuales la encontramos en su forma exterior, en su formato de presentación, en el origen e identidad de sus creadores, su finalidad y su duración:

\begin{tabular}{|c|c|c|}
\hline Formato & Creación & Duración \\
\hline $\begin{array}{l}\text { - Piezas informativas emitidas con } \\
\text { anterioridad en televisión: spot y } \\
\text { documentales. } \\
\text { - Campañas oficiales contra la drogadicción } \\
\text { emitidas con anterioridad en televisión. } \\
\text { - Vídeos creados a partir de diferentes piezas } \\
\text { informativas, publicitarias o de } \\
\text { entretenimiento. } \\
\text { - Vídeos creados para YouTube. }\end{array}$ & $\begin{array}{l}\text { - Vídeos realizados por organismos e } \\
\text { instituciones públicas o privadas. } \\
\text { - Vídeos creados por canales de televisión. } \\
\text { - Vídeos confeccionados por particulares } \\
\text { que únicamente han tenido proyección a } \\
\text { través de Internet. }\end{array}$ & $\begin{array}{l}\text { - Creaciones de gran formato, con } \\
\text { producciones que superan incluso } \\
\text { los cuarenta minutos. } \\
\text { - Producciones de formato medio, } \\
\text { donde se engloban aquellas que } \\
\text { superan los } 9 \text { minutos. } \\
\text { - De pequeño formato, en torno al } \\
\text { minuto de duración. }\end{array}$ \\
\hline \multicolumn{3}{|c|}{ Finalidad } \\
\hline \multicolumn{3}{|c|}{$\begin{array}{c}\text { • Informativa } \\
\text { - Divulgativa y preventiva }\end{array}$} \\
\hline
\end{tabular}

Teniendo en cuenta estas primeras anotaciones sobre las diferencias observables entre los vídeos seleccionados, realizamos el análisis de la recogida de información proporcionada por la ficha metodológica, donde comprobamos si estas variables también son influyentes o no en la recepción del mensaje.

\subsection{Aproximación a los resultados: ideas generales}

De las cinco dimensiones de estudio propuestas para el análisis se puede establecer una relación significante entre varios de los códigos del lenguaje audiovisual utilizados en los vídeos seleccionados que contribuyen a una mejor explicación de los previsibles efectos que tendrán en la audiencia juvenil. Así, centraremos la interpretación del análisis en el mensaje emitido desde su construcción formal y los elementos audiovisuales que incluye, separando en la interpretación a los personajes mostrados por su indudable importancia para el destinatario en la percepción del significado global del mensaje. Otras dos condiciones de estos productos audiovisuales parecen relevantes para contribuir a esa percepción y al posible éxito del mensaje: las características del formato y la interacción que ha provocado con los internautas.

Previamente, señalamos las ideas principales de cada una de las dimensiones estudiadas de modo sintético.

- Código audiovisual: No hay relación entre la autoría/creador del vídeo y la utilización de unos u otros elementos formales. La mayoría de los vídeos utiliza un código hablado y escrito (7), combinando elementos de audio e imagen. Dentro de éste, se sitúan los rótulos con frases, eslóganes o leyendas, e incluso la traducción del discurso de alguno de los personajes, como son aquellos de habla inglesa. Sólo dos de los vídeos analizados no cuentan con código escrito más allá de la información final sobre su autoría: "La droga y el sida", que es una representación teatral, y "Marea blanca 1/5", en formato documental televisivo. Hay tres vídeos de la muestra donde se emplea exclusivamente el código escrito acompañado de música de fondo en tono dramático: "Famosos usuarios de drogas", "Campaña mundial contra la droga" y "Una vida libre de drogas y alcohol". 
- Código audio: La relación entre el audio, bien sea música, la palabra de los personajes o los efectos de sonido, y el mensaje es total. No hay relación con su autoría, aunque son menos dramáticos en el uso de este elemento los contenidos realizados por profesionales de la comunicación (los documentales emitidos en televisión). Siete de los diez vídeos analizados utilizan la música como elemento significativo para subrayar el mensaje. En el caso de los dos programas documentales emitidos anteriormente en televisión, este uso se restringe en favor del empleo de efectos de audio y sonido ambiente de las localizaciones que aparecen en imagen. En algunos de ellos, incluso, la música es el único elemento auditivo presente: "La droga y el sida" o "El mejor spot contra las drogas (Bad Nigth)", por ejemplo.

La voz en off, con un narrador que conduce el relato, está presente en los documentales, de mayor duración. Los vídeos que reproducen declaraciones de personas afectadas por las drogas recurren por lo general a la presencia de los protagonistas (femeninos y masculinos, siempre jóvenes), a que se vean sus caras o fotografías, especialmente cuando relatan sus experiencias.

Por último, sólo en los dos documentales se muestran distintos puntos de vista sobre el consumo de drogas a través de los personajes entrevistados: familiares, amigos, médicos y protagonistas.

- Código visual: Es el elemento predominante en todos los casos. Se compone de fotografía estática en tres de ellos y de imágenes en movimiento en el resto. Sólo en un caso se trata de la grabación de un directo y en otros dos de la combinación de ambos y la presencia de imágenes de archivo. La mayoría de las piezas audiovisuales recurre a imágenes realistas donde se muestran con crudeza las consecuencias del consumo de drogas en los jóvenes y la influencia negativa que tiene en su entorno próximo. Uno de ellos, "Bad Nigth", realiza una representación distorsionada y delirante de lo que le ocurre a una joven cuando consume drogas durante una salida nocturna.

- Los personajes: La mayoría son jóvenes (8), de ambos sexos, de distintas razas y culturas, con mayoría blanca y clase media, media-alta. Las personas de otras edades representan claramente su entorno. La interacción entre ellos suele ser escasa o nula, a excepción de cuando aparecen en grupo en situaciones de ocio o diversión.

- El mensaje: El mensaje no está en el discurso. Mayoritariamente se encuentra en el lenguaje escrito, mediante las frases de los rótulos y los eslóganes, o en las declaraciones de los personajes que aparecen en los vídeos. Sea o no fuera de la narración o voz en off, el lenguaje utilizado es preferentemente formal. El tipo de mensaje más frecuente es el informativo, aunque se combina con las apelaciones continuas al espectador. Muchos de estos mensajes son en segunda persona, con oraciones imperativas, en línea con "no dejes que todo se vuelva feo" o “¿vas a dejar que esto te pase a ti?”. La idea de la muerte está implícita en todos los mensajes de forma clara, en algunos casos incluso de forma amenazante, "cada cigarrillo son cinco minutos menos de vida" de "Consecuencias de las drogas", por ejemplo. 


\subsection{El mensaje: elementos, percepción e interpretación}

Algunos investigadores apuntan que "el tratamiento informativo de los medios de comunicación en temas relacionados con la salud, y sobre todo con las drogas, se encuentra diversificado en dos niveles: 1) la búsqueda de un sensacionalismo exacerbado y 2) la descontextualización de la información", lo que influye negativamente en la credibilidad de la información transmitida (García del Castillo et al., 2011: 178; Costa, 2008). Por este motivo, cobra especial importancia el análisis del mensaje transmitido a través de los vídeos más vistos en YouTube, en aras a comprobar qué tipo de mensaje es el que cala en mayor medida entre los internautas. Según un estudio realizado en la Universidad de Elche tras encuestar a 115 estudiantes de Grado en Psicología, los resultados indican que un 53\% de los jóvenes utilizan Internet para obtener información sobre drogas, entre las que destacan el empleo de páginas especializadas $(66,1 \%)$, los buscadores $(52,2 \%)$, webs de instituciones especializadas $(50,4 \%)$, webs de fundaciones (40\%) y bases de datos (29,6\%) (García del Castillo et al., 2011: 180).

En nuestro estudio, si atendemos a la construcción del discurso, incluyendo dentro de éste el eslogan y la finalidad del mensaje, tenemos que las creaciones de carácter informativo y divulgativo son las mayoritarias. En general, se trata, además, de mensajes que, en un mayor número, siguen la regla de oro de las informaciones difundidas a través de los medios audiovisuales, es decir, emplean una combinación de textos, imágenes y sonidos, que son los tres elementos que de forma coordinada consiguen que las informaciones sean mejor recordadas y comprendidas por la audiencia (Benaissa, 2012, 218). Tres de las producciones analizadas - ¿Cómo funcionan las drogas? La cocaína", "La verdad sobre las drogas" y "Marea blanca 1/5"- se sirven de testimonios reales que relatan su experiencia con las drogas.

En todos los casos se lanza, en primer lugar, un mensaje negativo cuyo punto de partida es cómo se introdujeron en el mundo de las drogas para, posteriormente, transmitir que "se puede salir". Para ello, los testimonios reales se componen de hombres y mujeres con edades comprendidas entre los veinte y los cuarenta años, que en el relato de su experiencia exponen, sobre todo, por qué comenzaron a consumir este tipo de sustancias -"porque no encaraba la vida", "quería estudiar más", "quería tener más éxito", "para divertirme y probar nuevas experiencias"- y de la mano de quién lo hicieron -"de un amigo", "de mi padre", "de mi hermano"-. En un caso, además, la narración de los testimonios reales se complementa con las aportaciones realizadas por especialistas, donde también se hace referencia al negocio del narcotráfico, y en otro por familiares de drogodependientes que fallecieron a causa de su adicción.

Por otro lado, destaca el hecho de que dos de los vídeos -"La droga y el sida" y "Una vida libre de drogas y alcohol"- sean de carácter religioso. Lo más destacado de estas producciones es que en la construcción de su discurso predominan mensajes del tipo "si conocieras el amor que Dios te tiene, si descubrieras lo que él te quiere regalar" y "Jesucristo es la salida", con pasajes bíblicos: "yo estoy con ustedes todos los días hasta el fin de la historia" (Mt. 28.20) o "si uno escucha mi voz y me abre, entraré en su casa y comeré con él y él conmigo" (Ap. 3.20). 


\subsection{El formato y la duración no lo son todo}

De los diez vídeos analizados en este trabajo predominan aquellas producciones de pequeño formato y formato medio, entendiendo por éstas los trabajos audiovisuales que no superan los diez minutos de duración. De hecho, tan sólo uno de los vídeos objeto de la muestra supera los diez minutos. Se trata del documental "¿Cómo funcionan las drogas? La cocaína", de algo más de 43 minutos de duración, emitido con anterioridad a su difusión en YouTube por el canal de televisión Discovery Channel. En esta misma línea, aunque con una duración inferior, se encuentran dos trabajos más: "La verdad sobre las drogas", de casi ocho minutos de duración, y "Marea Blanca 1/5", en torno a los diez minutos, ambos emitidos con anterioridad a su proyección en la Red por un canal de televisión. No obstante, en este último caso cabe destacar que YouTube no ofrece la totalidad de la producción emitida previamente en televisión, sino que únicamente comprende un fragmento del trabajo total.

También en esta categoría de creaciones que han sido difundidas bien con anterioridad o de forma paralela en televisión y en Internet se incluyen los spot y las campañas auspiciadas por diferentes organismos, que en este trabajo están presenten con una producción cada uno. En el caso del spot, éste es el correspondiente a "Bad Night, esta noche te puede pasar a ti", un anuncio dirigido por el cineasta Alex de la Iglesia a petición de la Fundación de Ayuda contra la Drogadicción, y que fue considerado el mejor spot contra las drogas en el año 2009. El trabajo fue presentado a modo de tráiler cinematográfico que hacía apuntar al estreno de una nueva película de terror, y que era el preámbulo para la puesta en marcha de la campaña contra las drogas propiamente dicha. Su duración, de 31 segundos, se ajusta a la del resto de producciones de este tipo emitidas por televisión.

En lo que a las campañas se refiere, entre los diez vídeos más vistos en YouTube figura la campaña mundial contra la droga impulsada por la Fundación por un mundo libre de drogas, que dura algo más de un minuto. Sin embargo, resulta llamativo que, dentro de los vídeos analizados, se dividan la presencia a partes iguales aquellos elaborados por televisiones y diferentes organismos y los confeccionados por personas particulares. Así, en esta última categoría, se incluyen cinco producciones de variada naturaleza, entre los que predominan los montajes audiovisuales ("Famosos usuarios de drogas", "Una vida libre de drogas y alcohol", "Consecuencias de las drogas") e incluso teatrales ("La droga y el sida. Obra de teatro. El evangelio cambia"). En todos estos casos, Internet es el único canal por que el que se han difundido este tipo de creaciones.

Tabla 2. Formatos de los diez vídeos más vistos en YouTube sobre "jóvenes y drogas". Fuente: elaboración propia.

\begin{tabular}{|c|c|c|c|c|c|c|c|}
\hline \multicolumn{2}{|c|}{ Duración } & \multicolumn{2}{c|}{ Formato } & \multicolumn{2}{c|}{ Autor } & \multicolumn{2}{c|}{ Difusión } \\
\hline $\begin{array}{c}\text { Menos de } \\
5 \text { minutos }\end{array}$ & 4 & Documental & 3 & Canal TV & 3 & Televisión & 5 \\
\hline $\begin{array}{c}\text { De } 5 \text { a } 10 \\
\text { minutos }\end{array}$ & 5 & Spot & 1 & Instituciones & 2 & $\begin{array}{c}\text { Sólo } \\
\text { Internet }\end{array}$ & 5 \\
\hline $\begin{array}{c}\text { De } 11 \text { a } 20 \\
\text { minutos }\end{array}$ & 0 & Teatro & 1 & Particulares & 5 & & \\
\hline $\begin{array}{c}\text { De 21 a } 40 \\
\text { minutos }\end{array}$ & 0 & Videoaficionado & 4 & & & & \\
\hline $\begin{array}{c}\text { Más de } 41 \\
\text { minutos }\end{array}$ & 1 & Campaña & 1 & & & & \\
\hline
\end{tabular}


En cuanto a su aceptación por parte de la audiencia, internautas en este caso, los vídeos creados por organismos y televisiones y los confeccionados por videoaficionados ocupan puestos alternos en lo que al número de reproducciones se refiere. De hecho, dentro de los tres vídeos más vistos en YouTube -en los tres casos por encima de las 270.000 reproducciones- nos encontramos con que, a pesar de que el primer puesto, es ocupado por el documental emitido en Discovery Channel "¿Cómo funcionan las drogas? La cocaína" con más de 382.000 visitas, las otras dos creaciones corresponden al elaborado a modo de representación teatral, seguido del que muestra los efectos de las drogas en personajes famosos. En este caso destaca, además, que el primer puesto sea ocupado por el vídeo que cuenta con una mayor duración -superior a los 43 minutos- lo que pone de manifiesto que el tiempo que el usuario tenga que emplear en ver el vídeo no ha sido condicionante para descartar su visionado a favor de otros de menor duración.

Por lo demás, y atendiendo a la diferenciación entre producciones creadas por organismos y televisiones y las realizadas por videoaficionados, el reparto en el ranking de vídeos más vistos es el siguiente:

Tabla 3. Ranking según formato de los diez vídeos más vistos en YouTube.

Fuente: elaboración propia.

\begin{tabular}{|l|c||}
\cline { 2 - 2 } \multicolumn{1}{c|}{} & $\begin{array}{c}\text { Lugar que ocupan } \\
\text { entre los más vistos }\end{array}$ \\
\hline $\begin{array}{l}\text { Creaciones de organismos } \\
\text { y televisiones }\end{array}$ & $1^{\mathrm{o}}, 4^{\mathrm{o}}, 5^{\circ}, 6^{\circ}$ y $9^{\circ}$ \\
\hline $\begin{array}{l}\text { Creaciones de } \\
\text { videoaficionados }\end{array}$ & $2^{\mathrm{o}}, 3^{\circ}, 7^{\circ} \mathrm{y} 8^{\circ}$ \\
\hline
\end{tabular}

\subsection{Los destinatarios de las campañas: jóvenes y de ambos sexos}

En todos los vídeos analizados están presentes tanto la figura masculina como la femenina. Esto pone de manifiesto que desde los organismos y la ciudadanía en general, se asume la idea de que las drogas son un problema que afecta a todos por igual, sin que la distinción de género suponga una variable relevante, incluso, "en las últimas décadas se vienen observando cambios que han llevado a hablar de "feminización del uso de las drogas': uno es la disminución de las ratios que separa a varones y mujeres en el uso de drogas ilegales en las edades más jóvenes, y otro, un aumento progresivo del uso de drogas 'legales' entre todas las mujeres y en algunos grupos de edad. En concreto, tabaco, alcohol y fármacos" (Romo-Avilés, 2011: 92).

De los diez vídeos objeto de estudio, ocho muestran en imágenes a personas de ambos géneros. Además, muestran a otros personajes: consumidores y exconsumidores anónimos, especialistas en drogodependencias, familiares y amigos de drogodependientes y actores (contratados y/o famosos). Los testimonios e imágenes de drogodependientes (anónimos o conocidos) y actores contratados son los que están presentes en un mayor número de creaciones. Partiendo de la idea de que "las drogas han entrado en un proceso de normalización y existen la imagen de que lo normal, al menos entre los jóvenes, y especial, en espacios y momentos de ocio, es consumir, y este estereotipo, no justificado por la realidad, trabaja a favor del consumo, en una 
especie de profecía autocumplida" (Velázquez, 2010:65), el hecho de que víctimas de las drogas relaten su vivencia tiene especial repercusión en la sociedad. No en vano, el primero de los vídeos de la muestra de este trabajo más visitado es el emitido de forma previa por Discovery Channel, "Cómo funcionan las drogas. La cocaína", donde consumidores habituales de esta sustancia narran sus experiencias, mientras que especialistas británicos alertan de sus consecuencias.

Además de los consumidores, en las creaciones audiovisuales seleccionadas también encontramos testimonios de las víctimas colaterales de la drogas. Así, en "Marea blanca $1 / 5$ " narran su experiencia y drama con las drogas familiares y amigos que han perdido a seres queridos por culpa de la drogadicción. Junto a esto, nos encontramos con un vídeo, "Famosos usuarios de drogas", donde aparecen en imagen personajes conocidos del mundo del cine, la música o la moda que padecen o han padecido algún tipo de drogodependencia de la que también se va cuenta al internauta a través de un breve texto sobreimpreso en la pantalla acompañado de música.

Algunos de los nombres propios de los que se sirven en esta producción para alertar sobre las drogas y sus efectos son Amy Winehouse, Anthony Kiedis, Hillel Slovak, Cássie Eller, Cazuza, Fergie, John Lennon, Lindsay Lohan, Raul Seixes y Renato Russo. El vídeo, realizado y colgado en Youtube por un particular, contrasta con la presencia con la que, a lo largo del tiempo, han contado las drogas en la gran pantalla: "Por ejemplo, Humphrey Bogart con un cigarrillo entre los labios y una copa en la mano. (...) Al Pacino enterrando su rostro en una montaña de cocaína en Scarface; John Travolta inyectando atropina en el corazón de Uma Thurman después de una sobredosis en PulpFiction; Johnny Deep alucinando junto a Benicio del Toro en Miedo y asco en Las Vegas ..." (Pestaña, López y Sánchez, 2010: 107).

Se trata de fotogramas aislados que no sólo han encontrado reflejo en salas cinematográficas, sino también en la pequeña pantalla, donde en muchas series juveniles "el consumo y/o la presencia de drogas se presenta como una conducta habitual y cotidiana, incluso rutinaria, que no necesita motivo o justificación alguna. Se banaliza especialmente el consumo en el caso del alcohol y el cannabis aunque se dramatice la ingesta de otras sustancias como la cocaína.

\subsection{Drogas y redes sociales: participación ciudadana en la difusión del mensaje} La utilización creciente de las redes sociales por parte de los ciudadanos en todo el mundo es un hecho innegable, muy en especial entre los sectores más jóvenes de la sociedad. En España, según concluye el IV Estudio Anual de Redes Sociales (IAB, 2013), la penetración de las redes sociales “está alcanzado su madurez", puesto que 8 de cada 10 internautas de 18 a 55 años las utiliza. De ellas, Facebook es la que cuenta con una mayor aceptación entre los usuarios de redes sociales: el $99 \%$ de estos tienen Facebook, seguido de Twitter (87\%) y Tuenti (65\%) (IAB, 2013). La importancia de estas redes como canales de difusión de mensajes entre los jóvenes se está teniendo muy en cuenta desde las instituciones que quieren hacer llegar ciertas informaciones o campañas a unos destinatarios que viven conectados a Internet. En nuestro caso, el propio Plan Nacional sobre Drogas 2013-2016 estudia el uso de redes sociales, como Facebook o Twitter, para la difusión de sus mensajes para la prevención del abuso de alcohol y otras drogas entre los menores. 
Son pocos los estudios que tratan sobre el éxito de campañas institucionales o particulares a través de las redes sociales y prácticamente inexistentes las que analizan el éxito de éstas tras su difusión por esta vía. En cualquier caso, la referencia a redes sociales a nivel de estudios se centra más en Facebook, Twitter o Tuenti y menos en YouTube.

De todos los vídeos analizados, hay uno que destaca sobre el resto; se trata del documental de Discovery Channel "¿Cómo funcionan las drogas? La cocaína”, que acumula 294 comentarios y 1.743 suscripciones, además de haber sido 740 las personas que han mostrado su opinión sobre el documental a través de YouTube, Google+, Gmail, Orkut, Picasa o Chrome, marcando "me gusta" o "no me gusta", que son las opciones que este canal de vídeos ofrece para que los usuarios muestren su conformidad o desconformidad con los vídeos difundidos. Muy cerca, en lo que al número de suscripciones se refiere, se encuentra el vídeo "Consecuencias de las drogas", con 1.741, una cifra que contrasta con la poca participación con la que esta producción audiovisual cuenta respecto a los comentarios realizados, únicamente 10 , mientras que a través de una de las redes sociales promovidas por Google ha sido elegido por 69 personas.

Tabla 4. Comentarios, suscripciones y participación a través de las redes sociales.

Fuente: elaboración propia

\begin{tabular}{|l|r|r|r|r||}
\hline \multicolumn{1}{|c|}{ Vídeo } & Comentarios & Suscripciones & Me gusta & \multicolumn{1}{|c|}{$\begin{array}{c}\text { No me } \\
\text { gusta }\end{array}$} \\
\cline { 1 - 2 } $\begin{array}{l}\text { iCómo funcionan las } \\
\text { drogas? La cocaína }\end{array}$ & 294 & 1.743 & 671 & 69 \\
\hline $\begin{array}{l}\text { La droga y el sida, obra de } \\
\text { teatro El evangelio cambia }\end{array}$ & 99 & 1.088 & 831 & 31 \\
\hline Famosos usuarios de drogas & 78 & 36 & 108 & 43 \\
\hline La verdad sobre las drogas & 25 & 413 & 320 & 16 \\
\hline $\begin{array}{l}\text { El mejor spot contra las } \\
\text { drogas }\end{array}$ & 46 & 139 & 47 & 21 \\
\hline $\begin{array}{l}\text { Campaña mundial contra la } \\
\text { droga }\end{array}$ & 68 & 398 & 194 & 7 \\
\hline Malditas drogas & 63 & 5 & 18 & 17 \\
\hline $\begin{array}{l}\text { Una vida libre de alcohol y } \\
\text { drogas }\end{array}$ & 58 & 62 & 106 & 5 \\
\hline \hline Marea blanca 1/5 & ---- & 27 & ---- & ----- \\
\hline \hline Consecuencias de las drogas & 10 & 1.741 & 63 & 6 \\
\hline
\end{tabular}

La naturaleza de los comentarios realizados es dispar. ${ }^{4}$ Podemos distinguir entre:

- Comentarios que destacan la aportación positiva del vídeo: "excelente este documental"; "muy bueno";" que buen video lástima que sea tan largo: p"; "Muy Buen Video. Se Salvarán Muchas Vidas"; "excelente video, muy buen video, te felicito, me hiciste reflexionar mucho, yo no consumo nada y ahora que vi esto menos tu video lo usare para un trabajo de cívica".

4 De todos los vídeos, sólo hay uno, el correspondiente al documental "Marea blanca 1/5", que tiene desactivados todos los comentarios. 
- Comentarios que censuran el consumo de drogas: "la droga te quita familia te ase grosero con los que más te quieren"; "te quita oportunidades"; "te quita la dignidad y te puede mandar a la carsel [...]"; "las drogas no solo afecta a las personas que la consume, tambien afecta a su familia, se valiente si no puedes salir por tus propios medios del mundo de las drogas pide ayuda".

- Comentarios que aprovechan para contar su experiencia: "yo tomo LSD una vez cada 2 o 3 meses y lo hago solo, sin querer quedar de guays con nadie. Casi siempre me drogo solo, cuando yo quiero, no cuando los demás se drogan [...]. El LSD no es adictivo ni física ni mentalmente [...] no está de moda, por cierto [...] y nada tiene que ver con dios"; "excelente video es verdad en el caso mío afecte a mi familia a mi mama ella sufria mucho [...]"; "La maldita droga se a llevado muchas cosas de mi vida! me a quitado amigos, maldita droga química q se lleva mi vida poco a poco!".

- Comentarios que, aunque centrados en las drogas, desvirtúan el objetivo con el que ha sido creado y difundido el vídeo: "la mejor coca es la colombiana"; "le recomiendo a todo el mundo que pruebe el MDMA (éxtasis) al menos una vez en la vida. Le puedo asegurar que el 'viaje' va a ser muuuuy diferente al que se ve en ese quiero-y-no-puedo spot."

La participación ciudadana a través de las redes sociales más habituales, en este de las promovidas por Google (YouTube, Google+, Gmail, Orkut, Picasa o Chrome), "La droga y el sida" es la producción que cuenta con el mayor número de seguidores -862-, seguido de “¿Cómo funcionan las drogas? La cocaína” -con 740-mientras que el resto se sitúan por debajo de los 350 . No obstante, destaca el hecho de que la mayoría de los usuarios que se han servido de estas redes lo hayan realizado para expresar una opinión favorable del vídeo, ya que, en el conjunto de los diez vídeos analizados, las veces que los internautas han elegido el "me gusta" asciende a 2.358, frente a los 215 "no me gusta".

\section{Conclusiones}

Aunque en los últimos años Internet se ha convertido en un canal más a través del que difundir cualquier tipo de mensaje, los organismos e instituciones oficiales siguen prefiriendo los medios de comunicación tradicionales para la emisión de sus campañas contra la drogadicción. Esto no impide, sin embargo, que la Red canalice y difunda este tipo de mensajes, al tiempo que funciona como una ventana de distribución para aquellas creaciones realizadas por particulares y videoaficionados anónimos.

No obstante, tal y como se apuntaba en la hipótesis de partida, la recepción de estos vídeos a través de YouTube no es tan importante como a priori podía esperarse. De los vídeos analizados el que mayor número de reproducciones registraba tan sólo alcanzaba las 283.661 en un año, mientras que el que menos sumó 69.269 en cinco años. Estos datos contrastan con la popularidad que YouTube ha alcanzado entre los internautas, especialmente los más jóvenes, para la visualización de vídeos, siendo habitual que una producción audiovisual supere el millón de visitas en tan sólo unos días. 
Asimismo, el análisis realizado pone de manifiesto que, cuando se visualizan vídeos sobre los efectos y las consecuencias de las drogas, a los usuarios no les condiciona el formato, la duración o la autoría de los vídeos. Dentro de los diez vídeos de este tipo más vistos se encuentran tanto vídeos realizados por organismos oficiales, que anteriormente han tenido su difusión en televisión, como otros que han sido confeccionados por videoaficionados. Tampoco parece relevante la duración de los mismos a la hora de su consumo. No en vano, el que más reproducciones tiene es el de mayor duración, a la par que les interesan aquellos que personalizan el problema de las drogas de la mano de testimonios reales, tal y como se deduce por los comentarios realizados y por el número de reproducciones. Junto a esto, queda patente la concienciación de los internautas con el tema de las drogodependencias, no sólo por el número de reproducciones con el que cuentan los vídeos, sino también por la implicación que manifiestan como creadores, puesto que de los diez vídeos analizados, cinco han sido realizados por videoaficionados particulares.

En cuanto a la forma del mensaje, la mayoría de los vídeos responden a creaciones compuestas por palabra e imagen a la que en ocasiones se suma la música. Se trata de mensajes generalmente informativos que apelan directamente al espectador, bien a través de oraciones como "ser dependiente químico es una enfermedad", "te dejaste llevar", "las drogas son un negocio que se enriquecen con tu vida", "cuando tu peor enemigo crece en tu interior, no puedes escapar", "tú eliges", "un amigo de verdad no pone en peligro tu vida", bien a través del testimonio directo de víctimas de las drogas (consumidores y familiares o amigos).

Los mensajes de todas las producciones analizadas tienen como finalidad prevenir el consumo de drogas y ofrecer información relevante sobre sus consecuencias individuales y sociales, la importancia de la educación y una concienciación temprana, etc. Tratan, además, de motivar al abandono del consumo con alertas sobre la salud, el deterioro físico o ejemplos de cómo lo han sufrido otras personas. Y todos tienen un destinatario evidente, los jóvenes, fundamentalmente los comprendidos entre los 18 y 25 años, franja de edad que más niega la peligrosidad de las drogas (FAD, 2004).

En definitiva, tanto en la forma como en el contenido del mensaje o discurso de los vídeos analizados podemos concluir que las producciones de los últimos años no muestran cambios importantes en relación a las campañas de épocas inmediatamente anteriores: mantienen una predilección por la estructura dramática combinada con la informativa para emitir un mensaje negativo en clave de esperanza, orientado hacia la educación, los valores y la sensibilización social. Sin embargo, y excluyendo los dos productos más vinculados con la religión, ninguno ofrece claramente ayuda o apoyo al consumidor de drogas, ni informa de cómo puede obtenerla.

Por último, mientras los destinatarios de las campañas en general se muestran claros, no se pueden establecer valores de análisis seguros acerca de la percepción de estos contenidos difundidos a través de las redes entre la población juvenil.

\section{Referencias bibliográficas}

AIMC (2013): “Audiencia de Internet (octubre-noviembre 2013)". Disponible en: http://www.aimc.es/-Audiencia-de-Internet-en-el-EGM-.html (Recuperado el 20 de febrero de 2013). 
BENAISSA PEDRIZA, Samia (2012): "La comprensión y la retención del mensaje informativo por la audiencia de televisión". En Revista Icono 14, Vol.10 - No.3. DOI: 10.7195/ri14.v10i3.171

CENTRO DE INVESTIGACIONES SOCIOLÓGICAS (CIS) (2014): Barómetro de enero de 2014. Estudio ${ }^{\circ}$ 3011. Disponible en: http://www.cis.es/cis/opencms /ES/NoticiasNovedades/InfoCIS/2014/Documentacion_3011.html (Recuperado el 26 de febrero de 2014).

EDE Fundazioa (2010): Análisis de los anuncios televisivos de las campañas de prevención de drogodependencias y su incidencia en la población adolescente y juvenil. Servicio de Investigación Social. Gobierno Vasco. Disponible en: http://www.fundacionede.org/ca/archivos/investigacionsocial/presentacion-servicio-investigacion-social.pdf (Recuperado el 20 de febrero de 2014).

FUNDACIÓN DE AYUDA CONTRA LA DROGADICCIÓN (FAD) (2004): La percepción social de los problemas de drogas en España. Madrid, FAD.

GARCÍA DEL CASTILLO, José Antonio; GÁSQUEZ, Mónica; y GARCÍA DEL CASTILLO, Álvaro (2011): "Importancia de la credibilidad de las fuentes mediáticas en materia de drogas". En Miguel Hernández Communication Journal, $\mathrm{n}^{\circ}$ 2, pp. 173-196. Disponible en, http://mhcj.es/2011/09/22/garcia_gasquez_garcia (Recuperado el 3 de febrero de 2014).

JENKINS, Henry; PURUSHOTMA, Ravi; CLINTON, Katie; WEIGEL, Margaret; and ROBISON, Alice J. (2008): Confronting the Challengers of Participatory Culture: Media education for the 21st. Century. Chicago, The MacArthur Foundation. Disponible en: http://www.newmedialiteracies.org/files/working/NMLWhitePaper.pdf (Recuperado desde Revista INJUVE (2010), nº 88, pp. 96, el 27 de febrero de 2014).

LÓPEZ VIDALES, Nereida; MEDINA DE LA VIÑA, Elena; y GONZÁLEZ ALDEA, Patricia (2013): "Los jóvenes españoles demandan una televisión con más ficción y entretenimiento". En Ambitos: Revista internacional de comunicación, $\mathrm{n}^{\circ}, 22,2013$, pp. 191-200.

OBSERVATORIO EUROPEO DE LAS DROGAS Y LAS TOXICOMANÍAS (2013): Informe Europeo sobre Drogas 2013: Tendencias y novedades Luxemburgo: Oficina de Publicaciones de la Unión Europea. Disponible en: http://www.aragon.es /estaticos/GobiernoAragon/Departamentos/PresidenciaJusticia/Areas/PJ_04_Informacion_de_la\%20Union_europea/01_Europe_Direct_Aragon/Publicaciones $\% 20 \mathrm{de} \% 201 \mathrm{a} \% 20$ Uni $\% \mathrm{C3} \% \mathrm{~B} 3 \mathrm{n} \% 20$ Europea/Informe $\% 20$ europeo $\% 20$ sobre $\%$ 20drogas\%202013.pdf (Recuperado el 3 de marzo de 2013).

PEREIRA, Juan Ramón y ESPADA, José Pedro. (2009): "Las campañas publicitarias en la prevención del consumo de drogas". En GARCÍA DEL CASTILLO, José Antonio y LÓPEZ SÁNCHEZ, Carmen: Medios de comunicación, publicidad y adicciones. Madrid, Edad.

PESTAÑA, Beatriz; LÓPEZ, Cristina; y SÁNCHEZ, María (2010): "Desde el cigarrillo de Bogart a Hannah Montana, pasando (inevitablemente) por Trainspotting". 
En: Observatorio de Drogodependencias de Castilla-La Mancha, Jóvenes, Drogas y Comunicación, pp. 107-121.

PLAN DE ACCIÓN SOBRE DROGAS (España 2013-2016): Ministerio de Sanidad, Servicios Sociales e Igualdad. Disponible en: http://www.pnsd.msc.es/Categoria2/publica/pdf/PLAN_ACCION_SOBRE_DROGAS2013_2016.pdf (Recuperado el 5 de marzo de 2014).

ROBLES GAVIRA, Gabriel (2009): "Cambios y tendencias en el consumo de sustancias psicoactivas como factor de riesgo hacia la exclusión social". En Revista Inguruak, 45. Bilbao, AVSP, UPV-EHU, Universidad de Deusto, Gobierno Vasco, pp. 123-132.

ROMO-AVILÉS, Nuria (2011): "Cannabis, juventud y género: nuevos patrones de consumo, nuevos modelos de intervención". En Trastornos Adictivos. 2011, 13(3), pp. 91-93. Disponible en: http://apps.elsevier.es/watermark/ctl_servlet?_f=10\&pident_articulo $=90098140 \&$ pident_usuario $=0 \&$ pcontactid $=\&$ pident_revista $=182 \&$ ty $=121 \&$ accion $=$ L\&origen $=$ elsevier\&web $=$ www.elsevier.es\&lan $=\overline{e s} \& \mathrm{f}$ ichero=182v13n03a90098140pdf001.pdf (Recuperado el 23 de febrero de 2014).

TABERNERO, Carlos; ARANDA, Daniel; y SÁNCHEZ-NAVARRO, Jordi (2010): "Juventud y tecnologías digitales: espacios de ocio, participación y aprendizaje". En Revista de Estudios de Juventud (INJUVE), 88. Madrid, Ministerio de Igualdad, pp. 77-96.

VELÁZQUEZ MARTÍN, Roberto (2010): “Campañas de sensibilización social”. En Observatorio de Drogodependencias de Castilla-La Mancha, Jóvenes, Drogas y Comunicación, pp. 65-71. 